\title{
Canada gets cold feet
}

\section{Washington \& London}

IN a surprise move, the Canadian National Research Council (NRC) has announced that it will pull out of a major joint project with the United States and Britain to build two 8-metre optical/infrared telescopes.

The two telescopes, one in the Northern Hemisphere at Mauna Kea in Hawaii, the other to view the southern sky, probably at Cerro Pachon in Chile, will cost $\$ 176$ million to build, and are scheduled to be completed by 1998 . The plan was for half of this money to come from the US National Science Foundation, with the Canadian NRC and the British Science and Engineering Research Council splitting the rest of the cost equally. Canada's withdrawal should not delay construction of the Hawaiian telescope, which should begin next year, but if the second telescope is still to be built, another partner must be found to replace the Canadians.

Sidney Wolff, director of the US National Optical Astronomy Observatories, says she

\section{ENVIRONMENT}

\section{US blocks Antarctic}

\section{accord}

\section{Washington}

THE US delegation to a meeting of the Antarctic Treaty nations in Madrid last week blocked plans to sign a protocol that proposed a ban on mining in the continent for 50 years or more. As expected, the United States was alone among the 26 consultative parties to the Treaty in opposing the protocol (see Nature 351, 88; 9 May 1991). But because the Treaty requires consensus on any new protocols, the US position ended hopes of holding a symbolic signing ceremony on 23 June, the thirtieth anniversary of the enactment of the Antarctic Treaty, under which conflicting territorial claims to the continent were put aside.

State Department officials say that the United States could not sign a document that would have allowed a minority of Treaty nations to block a majority decision to relax a mining ban after 50 years. Under the draft discussed in Madrid, a decision to allow mining would require the agreement of all the present consultative parties. The US delegation instead put forward an alternative draft. This would allow a nation to withdraw from the mining ban, if a majority supported an amendment but a minority of nations were blocking the decision.

As a compromise, the other Antarctic Treaty nations changed this walkout clause to require a three-quarters majority in favour of an amendment. But the US delegation refused to sign even this version, saying that more time was needed to consider its implications.

Peter Aldhous is surprised by the timing of the decision and by the lack of prior consultation with project leaders in the United States. She had expected the NRC to defer its decision until two joint Canadian Natural Sciences and Engineering Research Council/NRC committees delivered their final verdicts on the telescope project. Instead, the NRC looked at preliminary versions of the committees' reports and decided that the project was too expensive.

In a letter sent to Canadian astronomers, Don Morton, director-general of the NRC's Herzberg Institute of Astrophysics, explains that the Council had to assume that its astronomy budget would not be increased. (The Canadian government is trying to control public spending in order to reduce the national budget deficit.) Given this, the letter says that even small cost overruns on the 8-metre telescopes would threaten Canada's other astronomy projects.

Canadian astronomers are lobbying hard for the project to be reinstated. Project scientist Gordon Walker, from the University of British Columbia, fears that if Canada withdraws from the 8-metre telescope project, its astronomers' access to US telescopes in the future will be restricted.

Morton says that the NRC's decision is not yet final. But a reversal seems unlikely, unless the Natural Sciences and Engineering Research Council or a foreign funding agency agrees to share the NRC's costs. Wolff is not optimistic about a Canadian change of heart, and is already looking for other partners to join the project. Morton's letter is "the firmest 'no' I have ever seen from a government agency," she says.

Wolff says she is disappointed by the NRC's move, but does not expect the project to be delayed as a result. The US and British contributions are enough to pay for the Mauna Kea telescope, and with no spending due on the Southern Hemisphere telescope for another two years, there is time to find a replacement for the Canadians, says Wolff.

The Canadian withdrawal is not the first funding problem to hit the 8-metre telescope project. Last year, the British contribution was delayed for two years, as part of the drive to prevent a $£ 40$ million budget shortfall at the Science and Engineering Research Council. Until the British can afford to contribute, the National Science Foundation is funding the project alone.

Many US astronomers would have preferred the project to have been funded in full by the National Science Foundation. In March, a National Academy of Sciences committee under John Bahcall, from the Institute of Advanced Study at Princeton, made a US (rather than a collaborative) opti$\mathrm{cal} /$ infrared 8-metre telescope at Mauna Kea its highest priority for funding in ground-based astronomy for the 1990s.

Peter Aldhous \& David Lindley
Japanese agency's faith in HOPE

\section{Tokyo}

JAPAN'S National Space Development Agency last week submitted an ambitious proposal for an unmanned space shuttle to service the Japanese module for the planned US Space Station. The proposed shuttle is twice the size of the one originally designed by the space agency and will be able to carry three times as much cargo into space.

The proposal came shortly after the US House of Representatives renewed its commitment to the space station by voting to spend \$1,900 million in fiscal 1992 for its development (see Nature 351, 507; 13 June 1991). If the Japanese government accepts the space agency's proposal for an enlarged shuttle, it will add considerably to Japan's already large financial commitment to the space station.

For several years, the space agency has been drawing up plans for an unmanned cargo shuttle to be called the "H-2 Orbital Plane", or HOPE, after Japan's nextgeneration $\mathrm{H}-2$ rocket that will carry the shuttle aloft. Last week's proposal, however, is the first time the agency has requested a budget to begin development.

The space agency has asked for $\mathbf{Y} 20,000$ million ( $\$ 140$ million) for the first threeyear phase of research and development, which would start next fiscal year. Agency officials are unwilling to provide total cost estimates for HOPE at this stage, but it will certainly add significantly to the $¥ \mathbf{3 0 0 , 0 0 0}$ million ( $\$ 2,100$ million) that Japan is already committed to spend on the Japanese module for the station. The shuttle is expected to be completed by 2000 .

Earlier plans called for a shuttle 7 metres long weighing 10 tons. But in the proposal submitted last week to the Science and Technology Agency, the space agency requests a shuttle 18 metres in length weighing 20 tons. The agency decided to increase the size of HOPE, says Mutsuhiko Masuda of the agency's public relations division, because a 10 -ton version would only be able to carry about one ton of cargo to the space station, and this would limit activity in the Japanese module. The 20-ton design will be able to carry 3 tons to the station and can carry 5 tons back to Earth.

Science and Technology Agency officials are not prepared to comment on the likely success of the agency's proposal. The proposal will first be examined by the Space Activities Commission, Japan's top space policy-making body, before the science agency decides whether to include it in its 1992 budget request, which will be submitted at the end of August.

David Swinbanks 